\title{
A Scoping Review of Associations Between Cannabis Use and Anxiety in Adolescents and Young Adults
}

\author{
Colleen Stiles-Shields ${ }^{1} \cdot$ Joseph Archer ${ }^{1,2} \cdot$ Jim Zhang $^{3} \cdot$ Amanda Burnside $^{4} \cdot$ Janel Draxler $^{1} \cdot$ Lauren M. Potthoff $^{4}$. \\ Karen M. Reyes ${ }^{1} \cdot$ Faith Summersett Williams ${ }^{4}$. Jennifer Westrick ${ }^{1} \cdot$ Niranjan S. Karnik $^{1}$ (D)
}

Accepted: 25 October 2021

(c) The Author(s) 2021

\begin{abstract}
Cannabis and anxiety are both rising issues that impact young people. This review seeks to explore the association between anxiety and cannabis in adolescents and young adults (AYA). A database search was run retrospectively from July 2020 through calendar year 2013. Articles had to present outcomes examining cannabis use and symptoms of anxiety, be written in English, contain samples with $\geq 50 \%$ who are age 25 or younger, and be published in a peer-reviewed journal. Fortyseven studies were identified that examined the relationship between anxiety and cannabis use. Twenty-three studies found a positive association that greater anxiety among AYA was associated with greater cannabis use. In contrast, seven studies found a negative association that greater anxiety was related to less cannabis use. And finally, 17 studies found no clear association between anxiety and cannabis use. Further research is needed to better understand the relationship between anxiety and cannabis use.
\end{abstract}

Keywords Cannabis $\cdot$ Anxiety $\cdot$ Adolescents $\cdot$ Young adults $\cdot$ Review

\section{Abbreviations \\ AYA Adolescents and young adults \\ PRISMA Preferred Reporting Items for Systematic \\ Reviews and Meta-Analyses}

Adolescence and young adulthood is a critical period of neurological and psychological development [1-3]. Due to the plasticity of the developing brain, young people are particularly susceptible to the environmental, social, and physiological factors that may contribute to the development and progression of mental illness and behavioral disorders [4]. According to the National Comorbidity Survey, the mean

Niranjan S. Karnik

niranjan_karnik@rush.edu

1 Department of Psychiatry and Behavioral Sciences, Rush University Medical Center, 1645 W. Jackson Blvd., Suite 302, Chicago, IL 60612, USA

2 School of Medicine and Public Health, University of Wisconsin, Madison, WI, USA

3 Rosalind Franklin University of Medicine and Science, Chicago, IL, USA

4 Ann \& Robert H. Lurie Children's Hospital of Chicago, Chicago, IL, USA age of onset for any mental health disorder is 14 [5]. Mental and behavioral problems in adolescence may impair neurological and emotional development, and, if unaddressed, these issues will likely extend into adulthood [5, 6]. This study examined the current literature on two of the most prevalent mental and behavioral issues among adolescents and young adults (AYA): anxiety and cannabis use.

Anxiety disorders (e.g. generalized anxiety disorder, social anxiety disorder) are highly prevalent among AYA and are associated with adverse outcomes later in life. The estimated prevalence of anxiety disorders in the United States is $31.9 \%$ for adolescents (ages 13-18) [7] and $14.7 \%$ for young adults (ages 18-25) [8]. The median age of onset for any anxiety disorder worldwide is 17 , making early recognition and prevention crucial [9]. Some anxiety disorders begin at even younger ages due to changes in social relationships in childhood and adolescence $[10,11]$; the median age of onset for separation and social anxiety disorders are 8 and 13, respectively [9]. Furthermore, anxiety disorders put AYA at greater risk for major depression, illicit substance dependence, reduced self-esteem, and educational underachievement in adulthood [11-13]. In addition to individual sequelae, anxiety disorders pose significant societal burdens, including lost work productivity and high medical resource use [14]. Indeed, the mean total annual cost per patient for 
pediatric anxiety is $\$ 6405$, with costs increasing with elevated symptoms of anxiety [15].

Cannabis use is also pervasive among AYA, particularly so with increased legalization in the United States, and has likewise been under scrutiny from researchers due to potential long-term consequences. According to the 2019 Monitoring the Future national survey, $35.7 \%$ of 12 th grade students, $28.8 \%$ of 10 th grade students, and $11.8 \%$ of 8 th grade students reported marijuana use within the past year [16]. Furthermore, according to the 2014 National Survey on Drug Use and Health (NSDUH), $1.09 \%$ of $12-17$ year-olds reported daily cannabis use, as did $6.51 \%$ of $18-25$ yearolds, the highest rate of any age category [17]. In 2014, only four states and the District of Columbia (D.C.) had legalized recreational cannabis use [18], but now, as of April 2021, recreational use has been legalized in 17 states, D.C., and Guam [19]. As cannabis legalization has expanded since the most recent national cannabis use rates were reported, it is possible that rates are even higher today [20, 21]. Furthermore, while there is conflicting evidence on the sequelae of early cannabis use [22], some studies have suggested a link between early use and adverse outcomes in adulthood such as illicit drug use, suicide attempts, and lower educational attainment [23, 24].

Both anxiety disorders and cannabis use have complex etiologies involving psychosocial, physiological, and environmental factors contributing to their development and progression [25-27]. It has been posited that anxiety may contribute to the etiology of cannabis use, or visa versa. However, this hypothesis is controversial, and the significance and directionality of the relationship has not been fully established [28-30]. Some research has found that cannabis may temporarily reduce anxiety symptoms, but the longterm effects of frequent cannabis use on mental health are unclear [29, 31, 32]. Cannabis use is common among those with anxiety disorders, but it is yet to be determined whether cannabis use itself contributes to the development and progression of anxiety disorders or if anxiety symptoms lead to cannabis use and potential dependence [31, 33]. Yet, despite this ambiguity, pediatricians today often receive questions from AYA, parents and caregivers about the potential use of cannabis as a treatment option for AYA patients with anxiety and other mental health problems [34].

The purpose of this scoping review was to describe the current state of scientific literature examining the relationship between anxiety and cannabis use among adolescents and young adults. The population of interest for this review includes AYA up to 25 years of age due to the high demand for information on cannabis as a treatment option for anxiety in pediatric clinics, which often provide care for patients well into young adulthood [35]. This topic is of particular importance to pediatricians due to the reported consequences of both early cannabis use and early onset of anxiety [11-13, 23, 24]. A literature search of recently published articles was conducted to elucidate current knowledge, identify gaps in the literature, and provide directions for future research. It is our intention that the information gathered in this review will inform clinicians and researchers interested in understanding and furthering current knowledge on cannabis use and anxiety in AYA.

\section{Methods}

\section{Search Strategy}

This review was conducted and reported following the Preferred Reporting Items for Systematic Reviews and MetaAnalyses (PRISMA) extension for scoping reviews [36] and was registered prior to data extraction in Open Science Framework (https://osf.io/zhxem/). A comprehensive literature search was run in the following databases: PubMed/ MEDLINE, Scopus, CINAHL, PsycINFO and Google Scholar. Both controlled vocabulary (i.e., Mesh terms) and keywords were searched. No restrictions were placed on the search in terms of language, date of publication, or geography (to best reflect the variable legal status of cannabis across different states). Animal studies were excluded. Additionally, a hand search was conducted of the reference lists of selected included studies and similar review articles. The search strategy was conducted collaboratively by two authors (CSS, JZ) and a trained medical librarian (JW) and the literature search was conducted by a trained medical librarian (JW) in July 2020. A reproducible search strategy is listed in Appendix 1.

\section{Inclusion and Exclusion Criteria}

For inclusion in the review, articles had to: (1) present outcomes directly examining real-life cannabis use and symptoms of anxiety (e.g., studies that broadly examined internalizing symptoms [combining depression and anxiety]; (2) be written in English; (3) contain samples with $\geq 50 \%$ who are 25 years of age or under; and (4) be published in a peerreviewed journal. As this review aimed to examine associations in real-world experiences, studies with methodologies that induced cannabidonal experiences in a lab environment were excluded. Technical validation papers, conference abstracts, review papers, and studies with subjects primarily older than 25 years of age were also excluded. At the full text review stage, articles published prior to 2013 were also excluded to target the recent literature associating cannabis use with anxiety symptoms in AYA. 


\section{Study Selection}

Covidence, an online systematic review service partnered with Cochrane [37], was utilized to facilitate study selection. From the literature search results, two reviewers independently screened all titles and abstracts against the inclusion criteria. Next, two independent reviewers reviewed full-text articles. Inclusion discrepancies at both stages were resolved through consensus with a third reviewer.

\section{Data Extraction}

Reviewer teams (JA, JZ, AB, JD, LMP, KMR, FSW) extracted data independently and in duplicate from all eligible studies using an online extraction form designed by the lead author (CSS) and housed on Google Forms. Discrepancies were resolved through review by the lead author.

\section{Data Synthesis}

A systematic narrative framework was utilized, classifying results based upon their findings associating anxiety with cannabis use (i.e., "Positive Association," "Negative Association," and "Unclear/No Association"). To contextualize the findings and promote future inclusive research methodological and reporting practices, study and sample characteristics and primary outcomes were included.

\section{Results}

\section{Included Studies}

See Fig. 1 for the PRISMA flow diagram. Following the removal of duplicate articles, 2886 titles and abstracts were independently reviewed in duplicate. Two hundred
Fig. 1 PRISMA flow chart

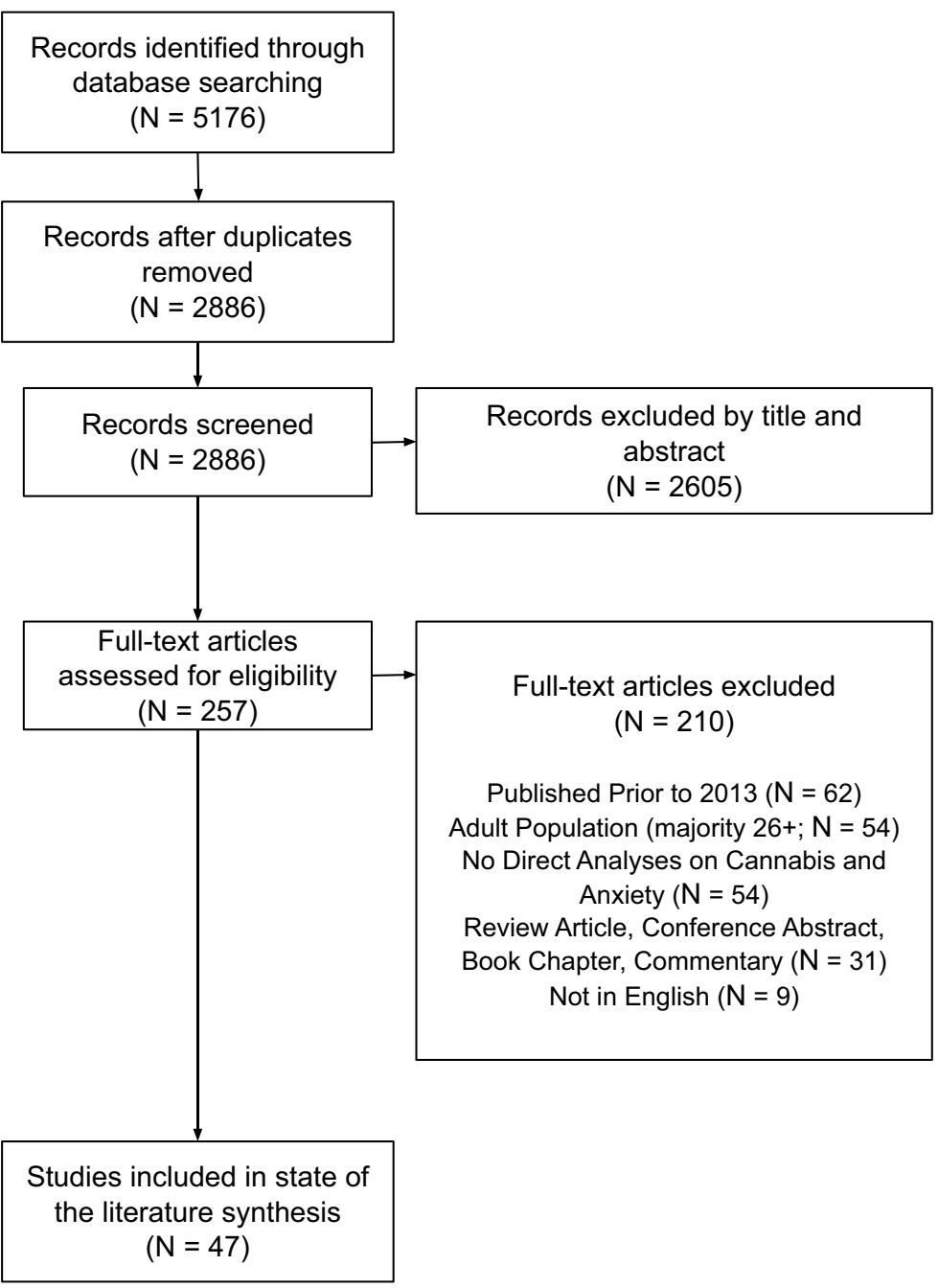


fifty-seven full-text articles were reviewed in duplicate for inclusion, with 47 articles selected for data extraction. Of the 47 studies: 23 reported a positive association (e.g., higher anxiety associated with earlier onset of use, higher frequency of use, and/or greater cannabis-associated problems); seven reported a negative association (e.g., higher anxiety associated with less use); and 17 reported an unclear or no association between anxiety and cannabis use. See Tables 1, 2 and 3 for the study characteristics.

\section{Positive Association}

\section{Study Characteristics}

Twenty-three epidemiologic and population-based studies identified a positive association between higher anxiety levels with cannabis use frequency, onset, and/or problems. These studies were conducted in eight countries: United States of America $(13 ; 56.5 \%)$, Canada $(4 ; 17.4 \%)$, Australia $(1 ; 4.3 \%)$, Chile $(1 ; 4.3 \%)$, France $(1 ; 4.3 \%)$, The Netherlands $(1 ; 4.3 \%)$, Norway $(1 ; 4.3 \%)$, and the United Kingdom (1; $4.3 \%)$. Notably, two studies from Canada derived from the Victoria Healthy Youth Survey, which prospectively assessed a community sample of 662 youth for ten years [38, 39]. Study settings included high schools, university or college campuses, community environments, urban/city environments, and rural environments. Cannabis use and/ or problems were assessed via: validated self-report questionnaires $(12 ; 52.2 \%)$, self-reported frequency of use (7; $30.4 \%$ ), or a multi-method approach (clinical interview with biometric data $[1 ; 4.3 \%]$ or with self-reported use $[1 ; 4.3 \%]$; validated self-report questionnaire with biometric data $[1$; $4.3 \%$ ]; self-reported use at one time point and a clinical interview at a later time point $[1 ; 4.3 \%])$. For the assessment of anxiety, validated self-report questionnaires (17; $73.9 \%)$, clinical interviews $(3 ; 13 \%)$ ecological momentary assessment $(1 ; 4.3 \%)$, self-reported diagnostic and treatment history $(1 ; 4.3 \%)$, and a combination of validated self-report questionnaire and biometric data $(1 ; 4.3 \%)$ were utilized.

\section{Sample Characteristics}

Sample sizes ranged from 76 to 36,714 , with females comprising $0-76.2 \%$ of the samples. No studies reported gender options beyond "male" and "female," with one exception which noted that three participants identified their gender as "Other"; however, these participants were excluded from gender-based analyses [40]. While all studies had at least half of their samples composed of participants 25 years of age or under, the range of included ages spanned six to 36 years of age. Seven studies (30.4\%) did not present any racial or ethnic identity information about their samples, with two more studies only providing the percentage of the sample that identified with one identity (e.g., "85\% White"). Four samples (17.4\%) had a minoritized racial or ethnic minority as the most represented group in their study.

\section{Primary Outcomes}

All 23 studies reported positive associations between anxiety or symptoms of anxiety with cannabis use, frequency of use, onset, and/or problems. Anxiety was associated with earlier cannabis initiation [41], higher cumulative lifetime use [42], use dependency [43], and general endorsement of use (as opposed to frequency of use) [44]. Further, frequent cannabis users were more likely than infrequent or non-users to meet criteria for anxiety disorders [45], endorse higher anxiety symptoms [39, 46], and/or display increases in anxiety over time $[39,47]$ or at a specific time period in adulthood (i.e., 26-27 years of age) [38]. Recent cannabis use was associated with greater anxious mood lability [48]. Similarly, longer abstinence from cannabis use was associated with less anxiety [42]. Also in line with these findings, those with anxiety disorders in childhood or adolescence were more likely to report persistent and problematic cannabis use as young adults (compared to those without problematic cannabis use who did not experience anxiety disorders early in life) [49].

Studies also reported associations with specific types of anxiety, as well as potential mediators and moderators. Generalized and social anxiety were both associated with cannabis-related problems (but not use) [50-52], with social anxiety also being associated with more problem severity [53] and generalized anxiety associated with use frequency (as opposed to endorsement of any use) [50,54]. Cannabis users were also more likely to endorse higher separation anxiety in adolescence compared to non-users [55]. Anxiety sensitivity was associated with cannabis-related problems [56] and more negative effects of cannabis [57]. Use of higher potency cannabis was associated with moderate elevations in the likelihood of meeting criteria for generalized anxiety disorder [58]. Gender moderated the relationship between problematic use with anxiety (stronger for females) [40]. Certain genotypes (i.e., short allele carriers vs. non-carriers) were also identified as moderators of the relationship between higher cannabis use and anxiety symptoms [59]. Finally, negative urgency (the tendency to act impulsively in the face of stress) mediated associations between cannabis use with generalized anxiety disorder, panic disorder, and social phobia [60].

\section{Negative Association}

\section{Study Characteristics}

Seven epidemiologic and population-based studies identified a negative association between anxiety levels and cannabis 


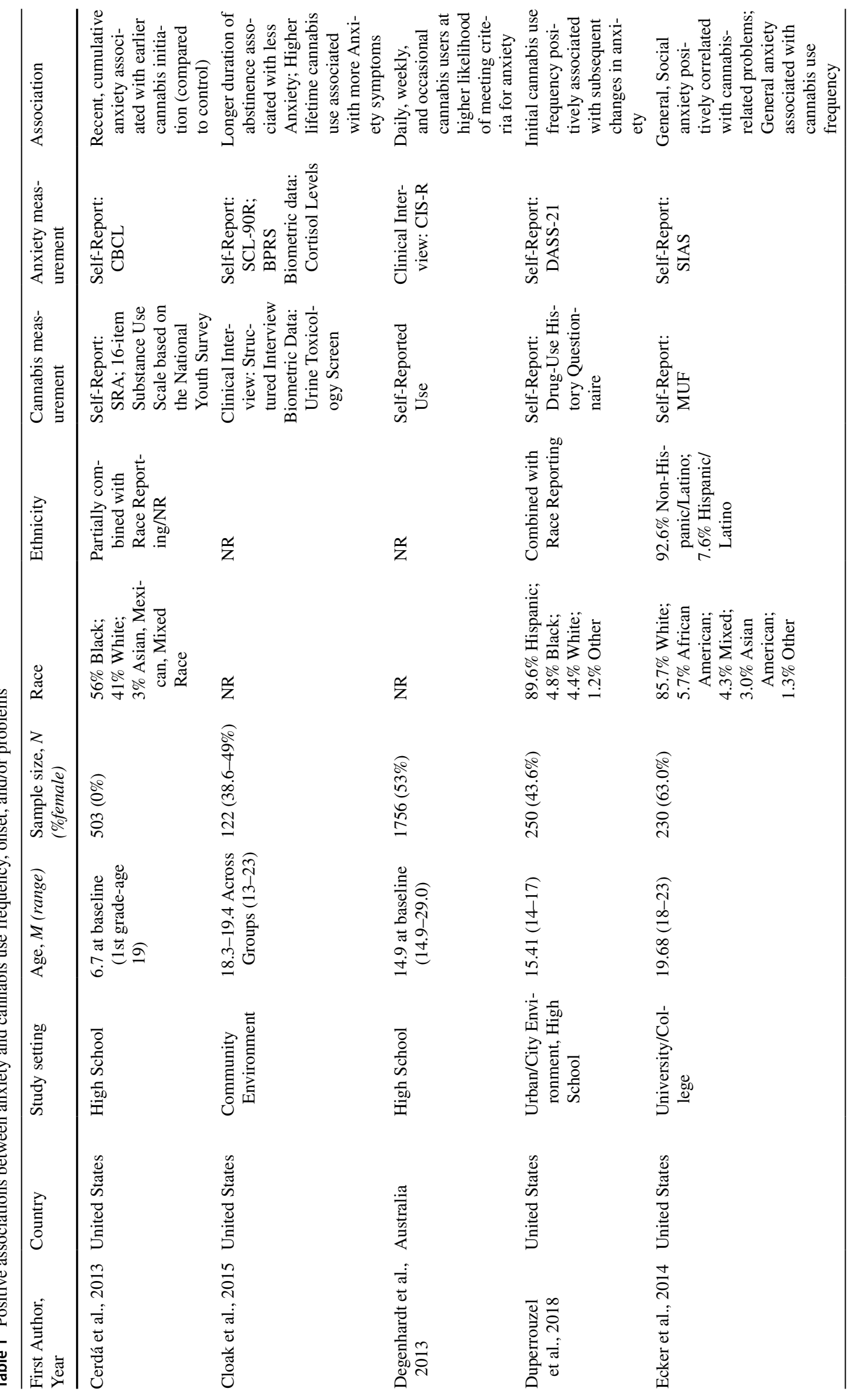




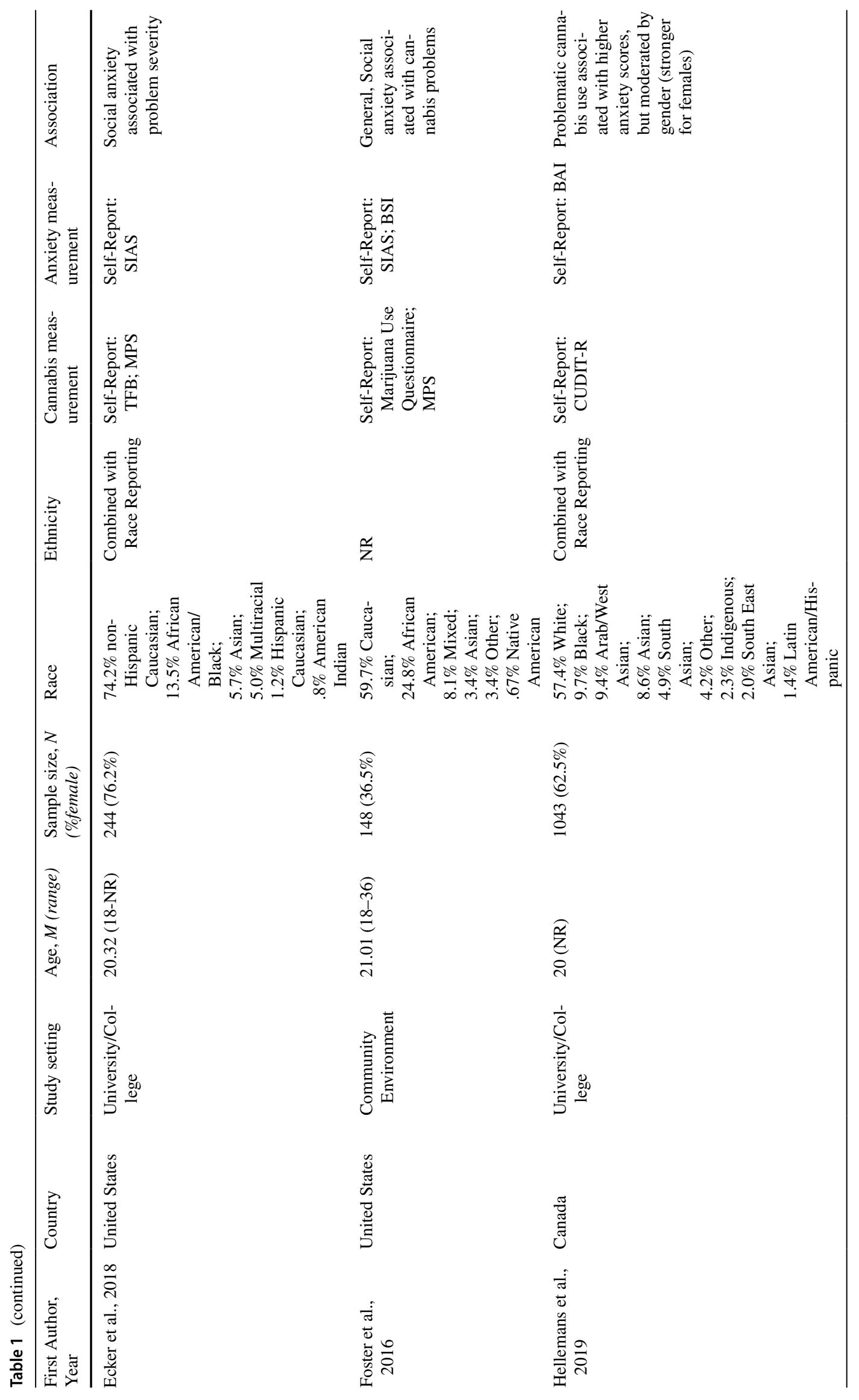




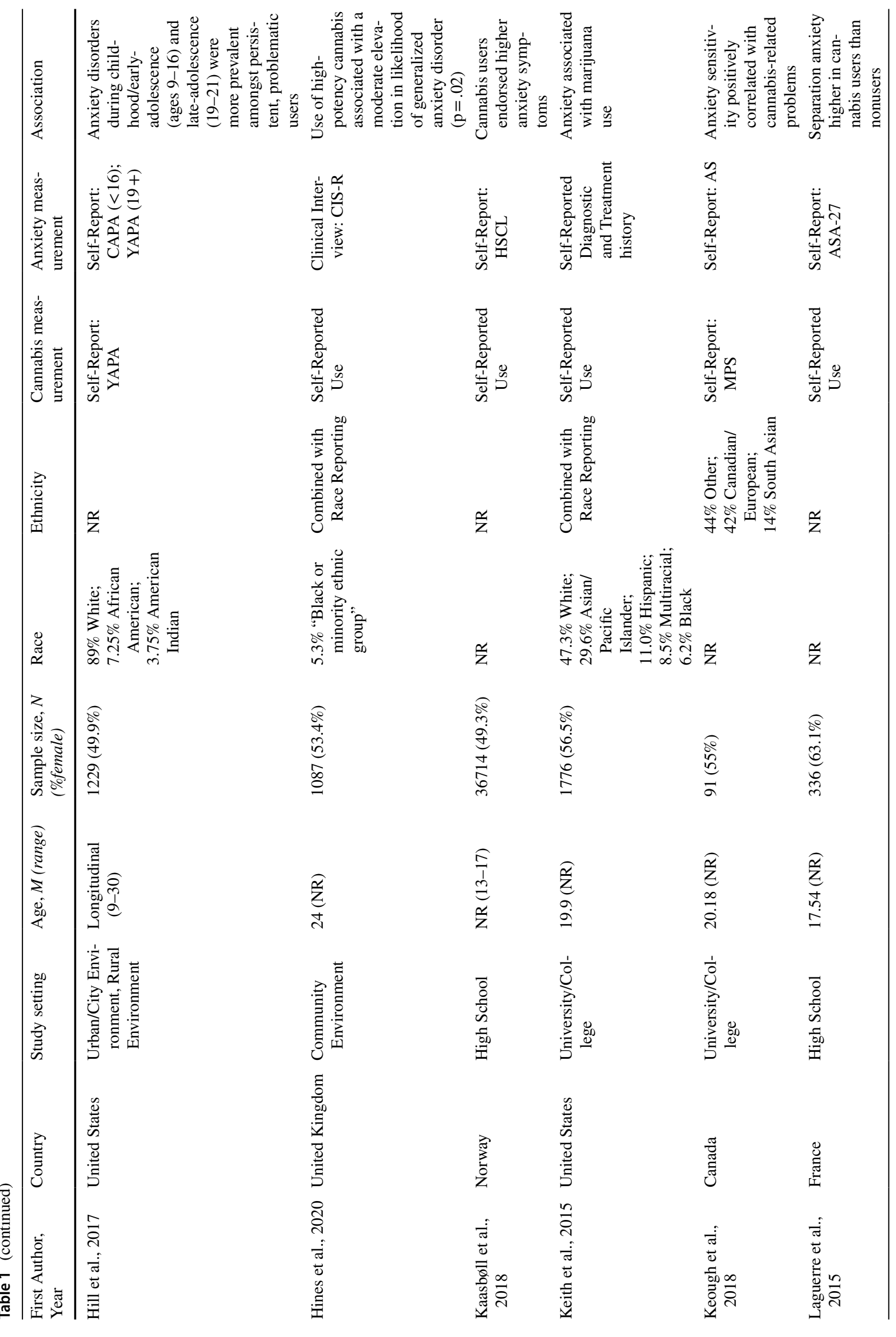




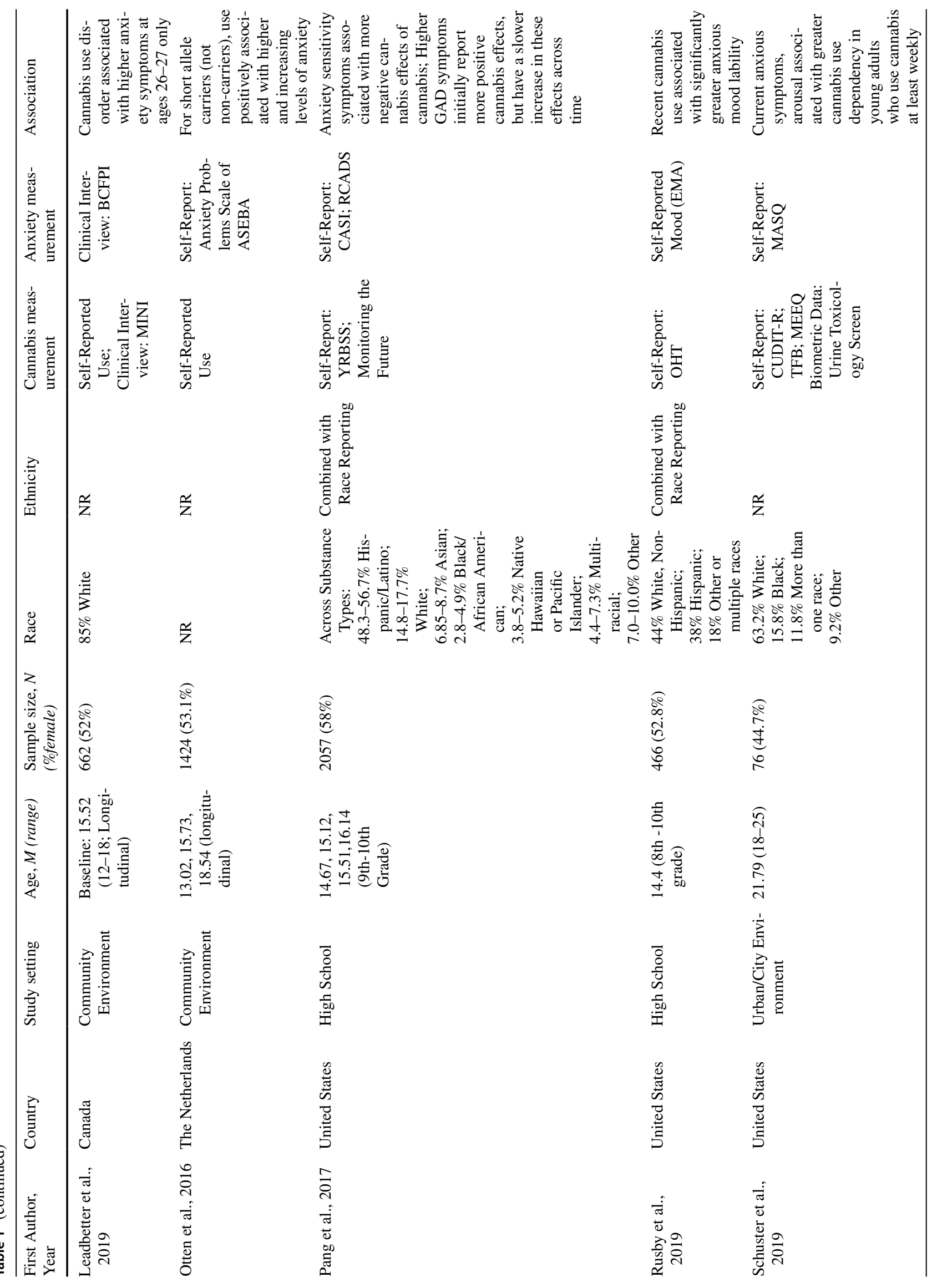




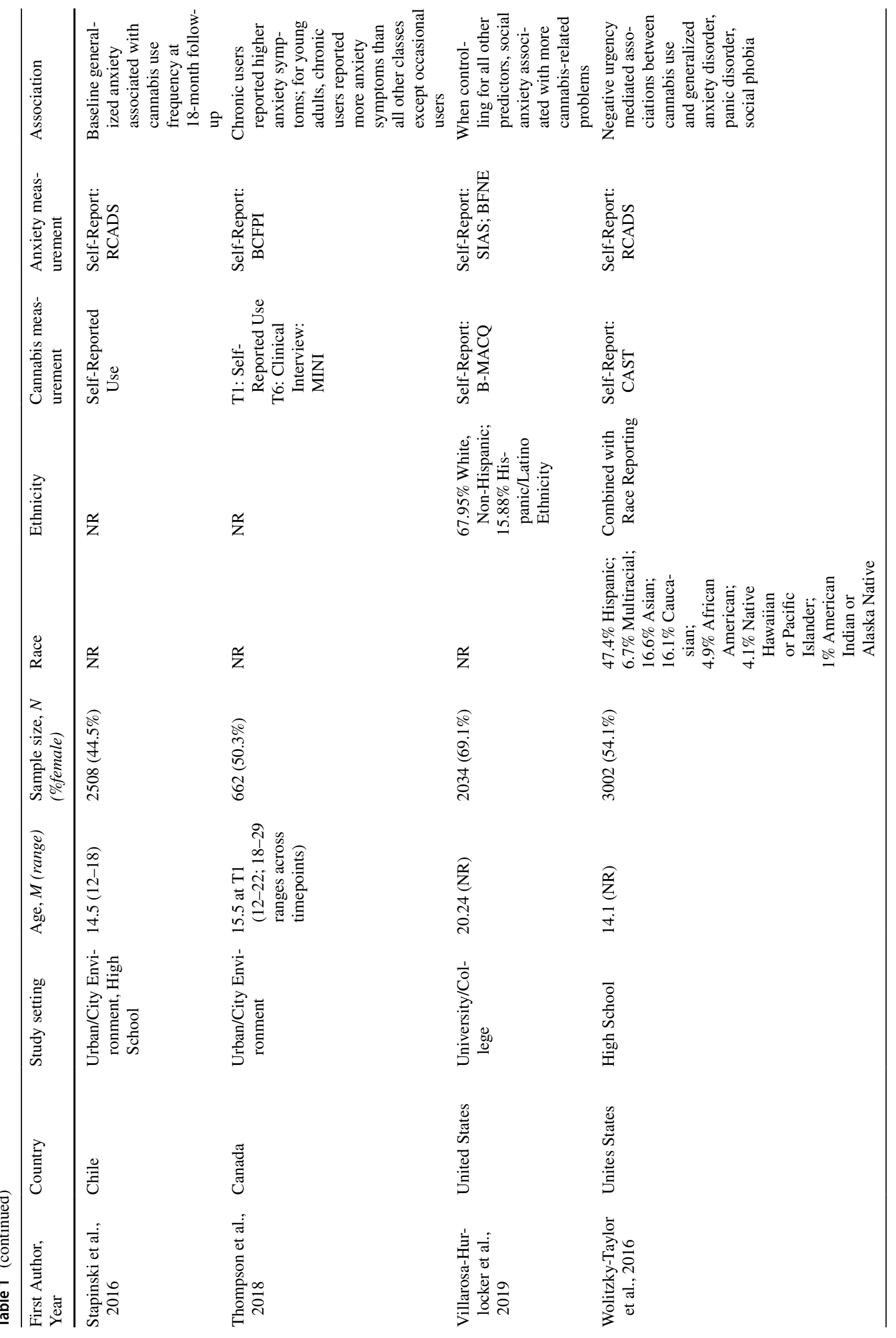




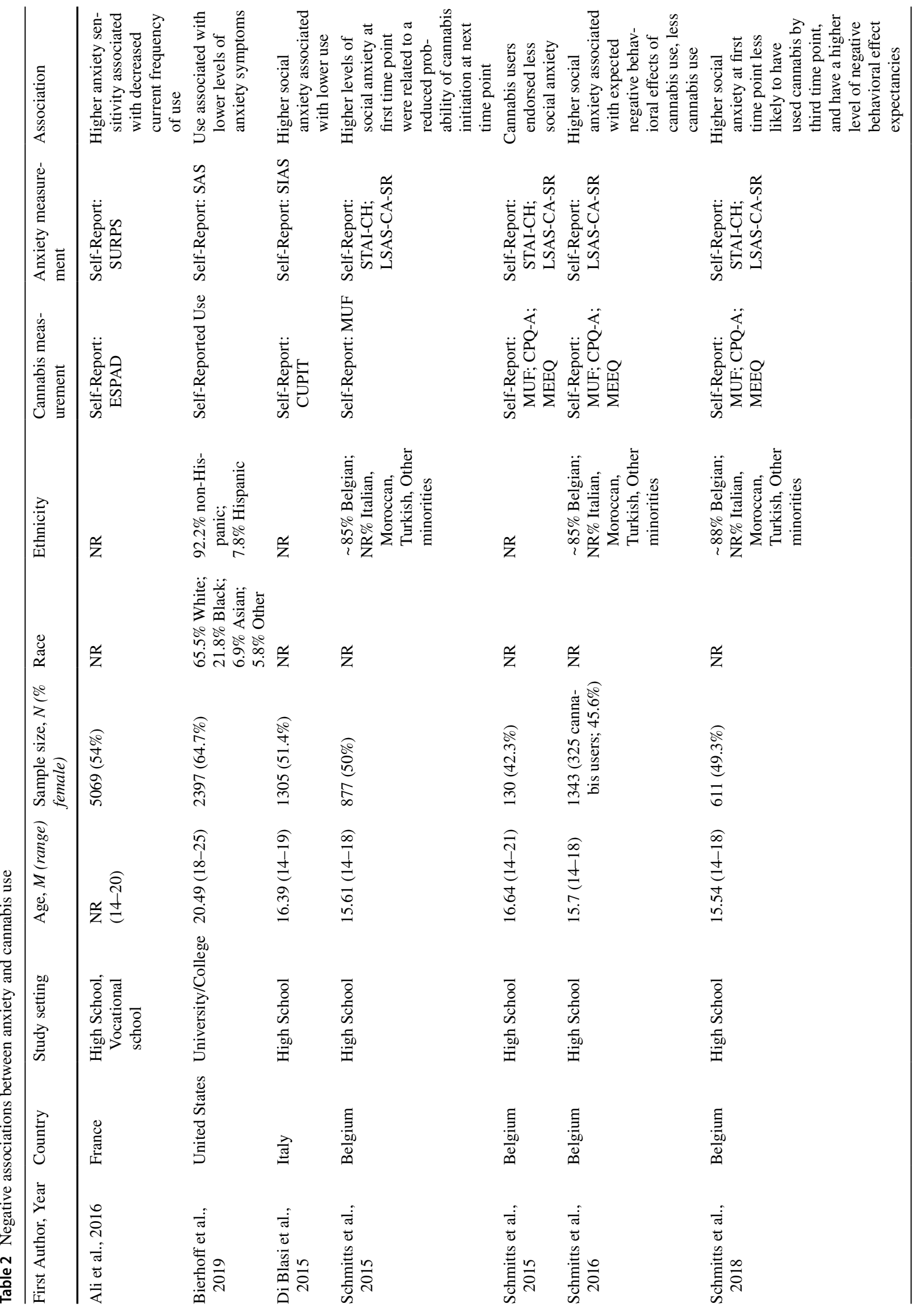




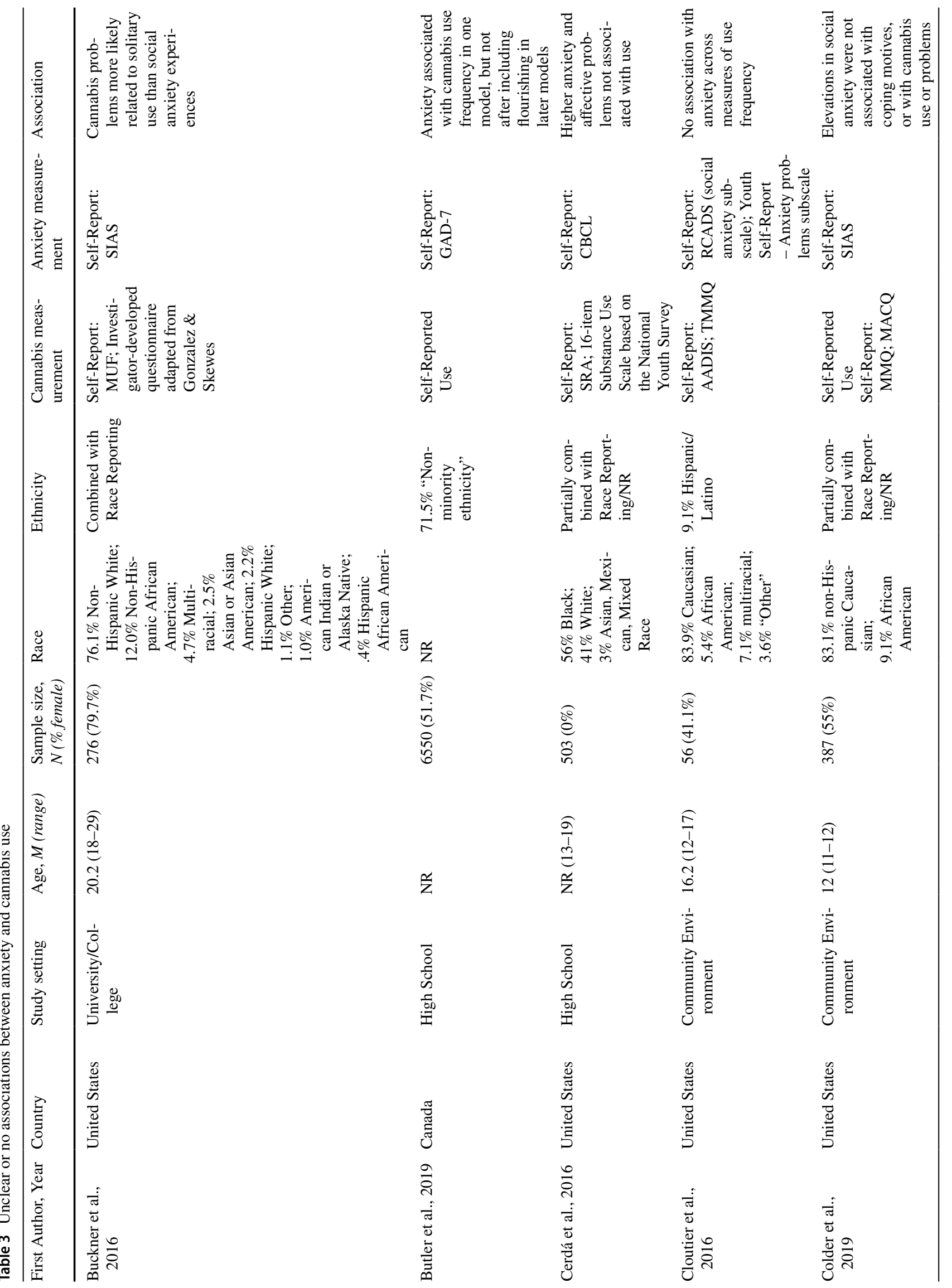




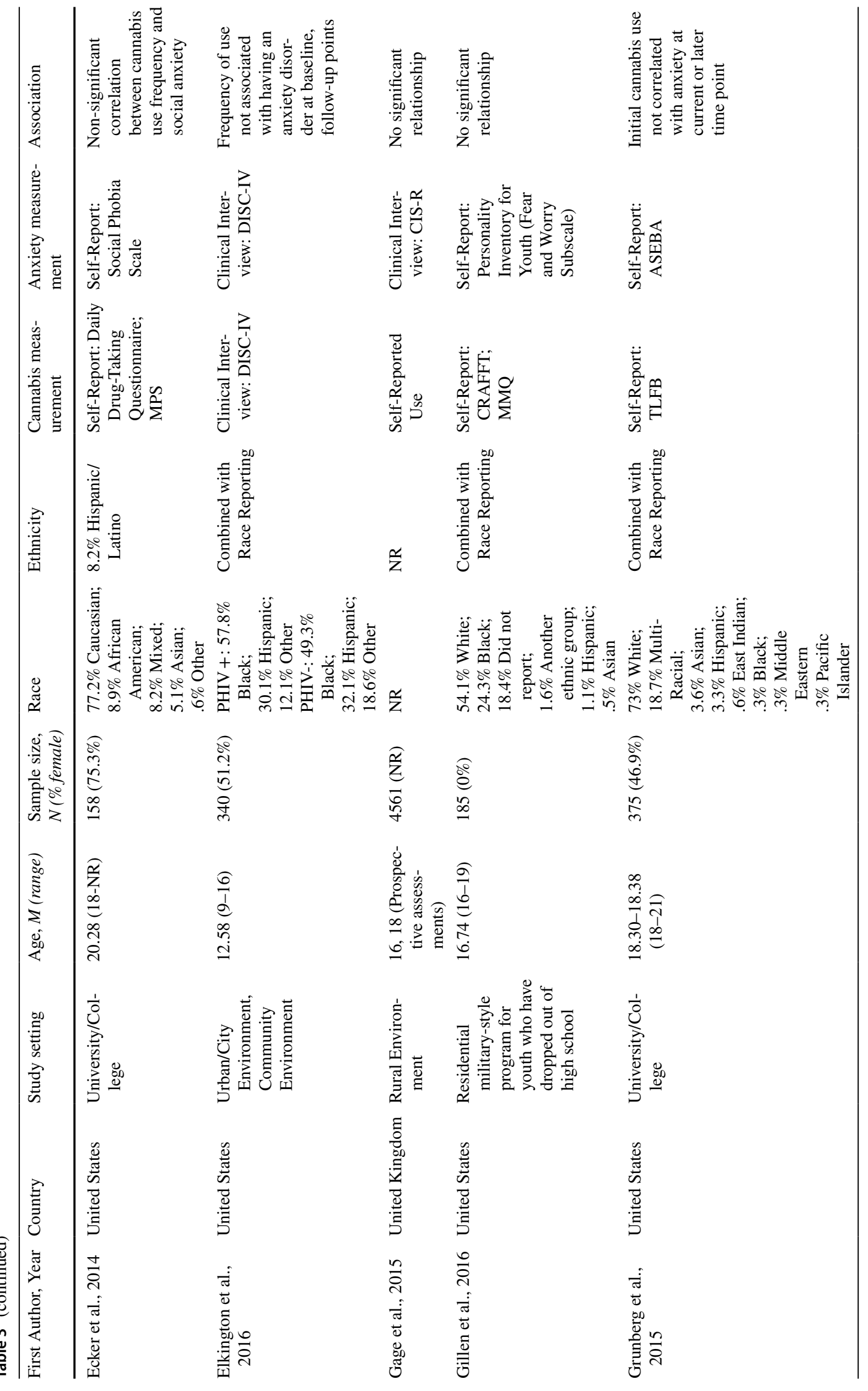




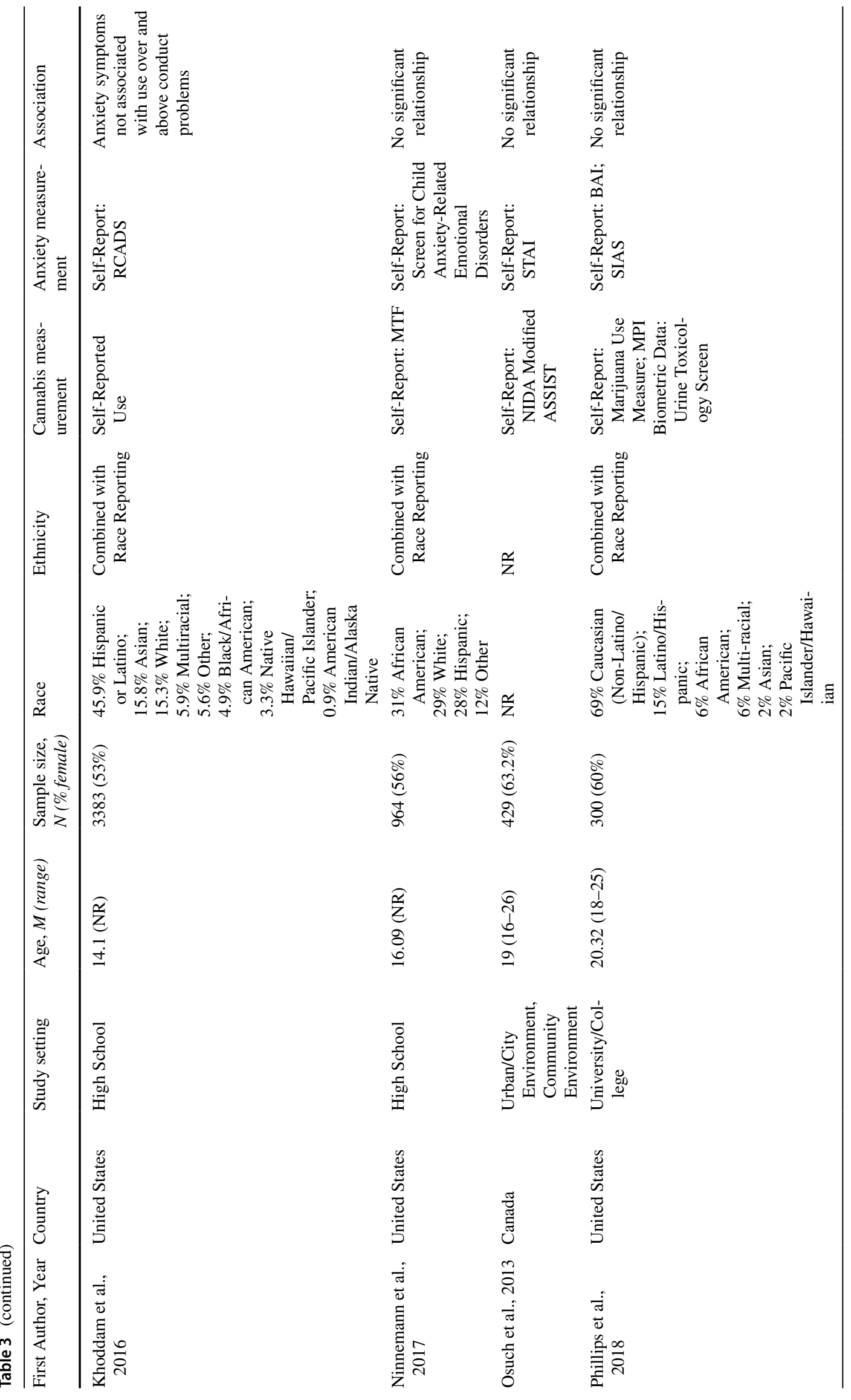




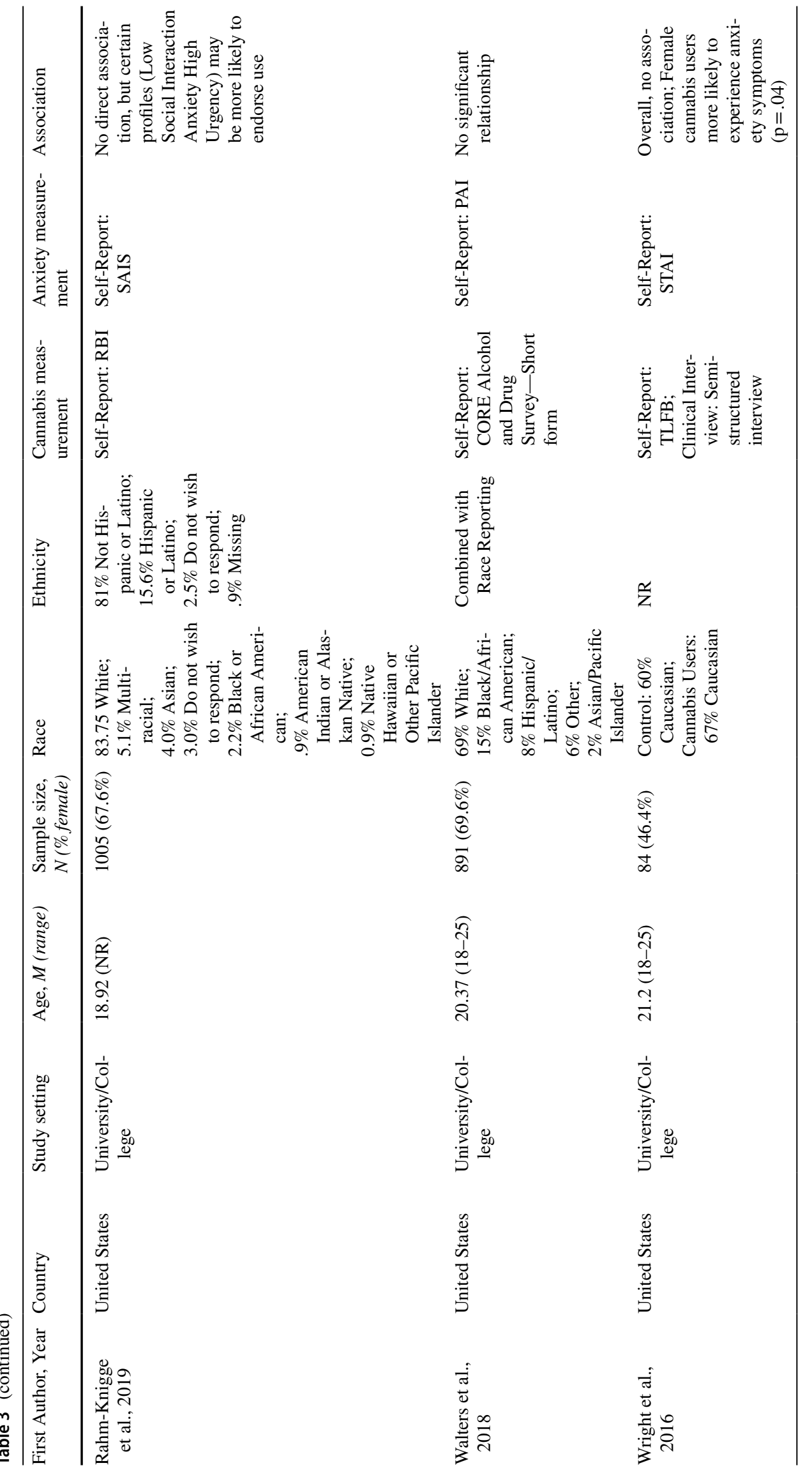


use. These studies were conducted in four countries: Belgium $(4 ; 57.1 \%)$, France $(1 ; 14.3 \%)$, Italy $(1 ; 14.3 \%)$, and the United States of America $(1 ; 14.3 \%)$. Notably, the studies occurring in Belgium were from the same research group and high school setting. Study settings included high schools, vocational schools, and university or college campuses. Cannabis use and/or problems were assessed via validated self-report questionnaires $(6 ; 85.7 \%)$ or self-reported frequency of use $(1 ; 14.3 \%)$. All seven studies used validated self-report questionnaires to assess anxiety.

\section{Sample Characteristics}

Sample sizes ranged from 130 to 5069, with females comprising $42.3-64.7 \%$ of the samples. No studies reported gender options beyond "male" and "female." The samples were mostly adolescent, ranging from 14 to 19 years of age. Three studies (42.9\%) did not present any racial or ethnic identity information about their samples, with three more studies only providing the percentages of the sample based on ethnicity (i.e., Hispanic/non-Hispanic; Belgian/Italian, Moroccan, Turkish, Other minorities).

\section{Primary Outcomes}

All seven studies reported a negative association between anxiety and cannabis use. Indeed, cannabis use in the last 30 days was associated with lower levels of overall anxiety symptoms compared to non-users [61] and lifetime cannabis use was associated with less social anxiety compared to non-users [62]. Specific types of anxiety were also noted with these negative associations. Namely, higher anxiety sensitivity was associated with decreased frequency of cannabis use [63]. Higher social anxiety was associated with non-use compared to moderate and risky cannabis use [64, 65] and was also associated with a reduced probability of cannabis initiation over time $[66,67]$. Social anxiety was hypothesized as protective due to its association with more expectations of negative behavioral effects from the use of cannabis [65, 67].

\section{Unclear or No Association}

\section{Study Characteristics}

Seventeen epidemiologic and population-based studies did not identify significant evidence to associate anxiety and cannabis use. These studies were conducted in three countries: the United States of America (14; 82.4\%), Canada (2; $11.8 \%$ ), and the United Kingdom (1; 5.9\%). Study settings included high schools, university or college campuses, community environment, urban/city environment, rural environment, and a residential military-style program for youth who have dropped out of high school. Cannabis use and/or problems were assessed via: validated self-report questionnaires $(10 ; 58.8 \%)$, self-reported frequency of use $(3 ; 41.2 \%)$, clinical interview $(1 ; 5.9 \%)$, or a multi-method approach (validated self-report questionnaire with self reported use $[1 ; 5.9 \%]$, with biometric data $[1 ; 5.9 \%]$, or with a clinical interview $[1 ; 5.9 \%])$. Fifteen studies (88.2\%) used validated self-report questionnaires to assess anxiety, and two studies used a clinical interview (11.8\%).

\section{Sample Characteristics}

Sample sizes ranged from 56 to 6,550, with females comprising $0-79.7 \%$ of the samples. One study did not report sex and no studies reported gender options beyond "male" and "female." While all studies had at least half of their samples composed of participants 25 years of age or under, the range of included ages spanned 11 to 29 years of age. Two studies $(11.8 \%)$ did not present any racial or ethnic identity information about their samples, with two studies (11.8\%) only providing the percentage of the sample that identified with one identity (e.g., "60\% Caucasian;" "71.5\% Non-minority ethnicity"). Four samples (23.5\%) had a minoritized racial or ethnic population as the most represented group in their study.

\section{Primary Outcomes}

None of the 17 studies identified significant associations between anxiety and cannabis use. Specifically, anxiety and social anxiety were not significantly associated with use [68-78], use frequency [79-81], problems [69, 74, 82], or coping motives $[69,83]$. Unclear findings also occurred, such as an association appearing in one model of a study, but losing significance as additional variables were added to later models [84]. Other factors were also identified that potentially are associated both with having anxiety and/or cannabis use, such as conduct problems [78], solitary cannabis use [82], having certain personality profiles (e.g., low social interaction anxiety with high urgency) [75], or being a female cannabis user [77].

\section{Discussion}

The current scoping review synthesized the recent literature examining potential associations between anxiety and cannabis use in AYA. The studies that met inclusion criteria were internationally representative, included longitudinal and cross-sectional data, and ranged in sample sizes from 56 to 36,714 . High variability was present in terms of methodological approaches, including the assessment of anxiety and cannabis use to collecting and reporting 
sample characteristics (e.g., gender, race). Most crucially to this review, studies indicated mixed findings regarding the relationship between anxiety and cannabis use in AYA. Indeed, nearly half of the studies identified a positive association between higher anxiety levels with cannabis use frequency, onset, and/or problems; a little over three quarters were unable to identify a significant association; and a minority identified a negative association, such that those with higher anxiety (often social anxiety) had lower use and/or problems.

The clinical implications of the current state of research are mixed. Clinicians often meet with adolescents who use cannabis presenting with anxiety as the reason for their cannabis use. With the legalization of cannabis across multiple jurisdictions in the U.S., the potential for adolescents' expanded access to cannabis is highly likely. Clinicians need to be vigilant in asking adolescents about cannabis and make attempts to understand the dynamics of its use. One helpful clinical question is to query the youth whether the anxiety began before or after the initiation of cannabis. This might help guide the discussion and clinical decisions about the intersection of these experiences. Finally, it is likely that if the adolescent tries to reduce cannabis use, they might experience transient rebound anxiety symptoms. Discussion of how to address these symptoms might help youth who wish to make a change in their patterns of use.

There is substantial need for additional research in this domain. In particular, there is a need to conduct a large, prospective cohort study that tracks the onset of anxiety as well as cannabis, and clearly delineates the connections between these phenomena. In addition, it is also important to examine differential predictors of both anxiety and substance use among marginalized or underrepresented groups of adolescents. The use of consistent methodological approaches, measures, and outcomes would increase generalizability of these studies and allow linkage in the event that studies of various populations are done independently.

There are several limitations to the current review. First, it was focused on anxiety and cannabis and, as such, excluded many other domains of psychiatric experience and substance use. The degree of comorbidity for both anxiety and cannabis use often intersects with other phenomena that may not be well represented in this scoping review. Second, this review focused on literature and research published in English. Both cannabis and anxiety are very much global experiences and there is a possibility that some important literature might have been excluded. Third, it should be noted that several studies used relatively limited sampling, heterogeneous definitions, and a range of sample sizes that in aggregate might reduce generalizability.

\section{Summary}

Anxiety and cannabis use are highly common among adolescents and young adults (up to age 25). The rising movement to legalize recreational use of cannabis is likely to further expand the presence of this substance in various forms. In this scoping review of the literature, 47 studies were identified that examined the relationship between anxiety and cannabis use. Of these studies, a plurality of 23 studies found a positive association that greater anxiety among AYA was associated with greater cannabis use. In contrast, seven studies found a negative association that greater anxiety was related to less cannabis use. And finally, 17 studies found no clear association between anxiety and cannabis use. In aggregate, these findings present a mixed picture with unclear outcomes. There is a significant need to more rigorously examine the association between anxiety and cannabis use, and to pay particular attention to factors that might be unique to underrepresented groups.

\section{Appendix 1: Literature Search Strategy}

Reproducible Search Strategy: PubMed

(((anxiety disorders[MeSH Terms]) OR (anxiety OR panic OR agoraphobia OR phobia))

AND ( ( ( "Cannabinoids"[Mesh]) OR "Cannabis"[Mesh]) OR "Marijuana Abuse"[Mesh]) OR “Marijuana Smoking"[Mesh] OR "Medical Marijuana"[Mesh] OR CBD OR cannabis OR cannabinoid* OR cannabidiol* OR cesamet OR dronabinol OR endocannabinoid* OR hashish OR hash OR levonantradol OR marijuana OR marihuana OR Nabilone OR THC OR tetrahydrocannabinol OR pot OR weed))

AND (adolescent[MeSH Terms] OR Adolescen* OR "high school" OR "middle school" OR "elementary school" OR "secondary school" OR "secondary education" OR "grade school” OR juvenile* OR kid OR kids OR minor* OR paediatric* OR pediatric* OR pediatrics OR teen* OR young OR youth*))

NOT ((“animals"[MeSH Terms] NOT "humans"[MeSH Terms]) OR mice[tiab] OR rat[tiab] OR rats[tiab])

Search Terms 


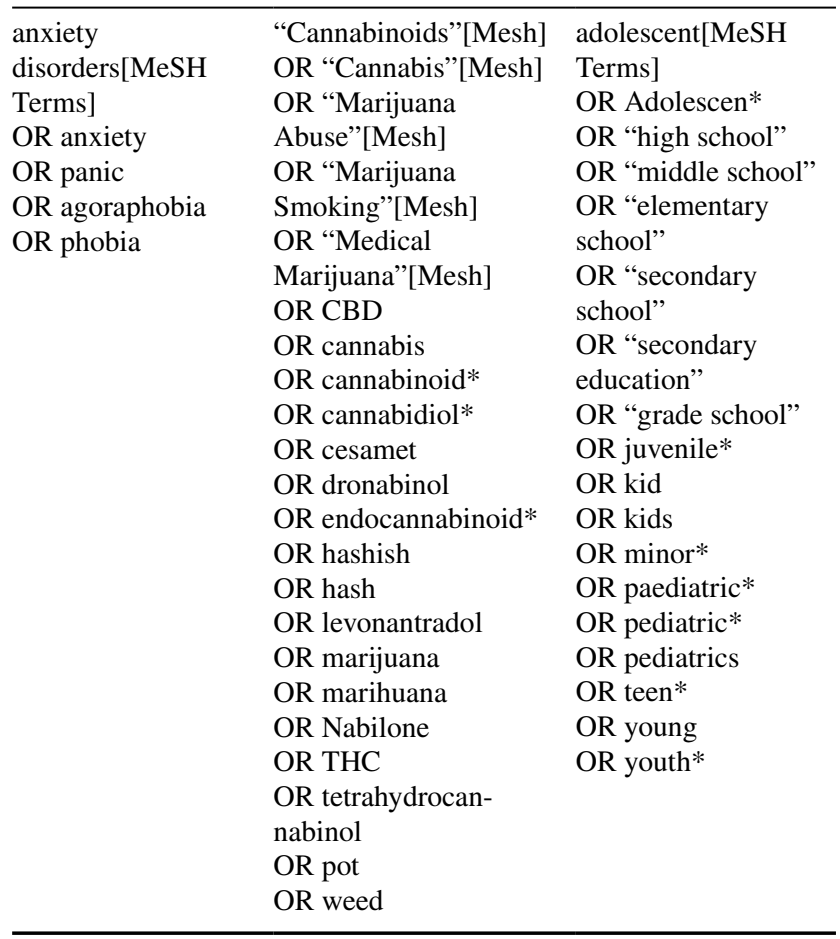

NOT animals

Supplementary Information The online version contains supplementary material available at https://doi.org/10.1007/s10578-021-01280-w.

Author Contributions Dr CSS conceptualized and designed the study, conducted and oversaw the review of abstracts and papers, drafted the initial manuscript, and reviewed and revised the manuscript. $\mathrm{Mr}$ JA conducted background literature searches, wrote portions of the manuscript, reviewed abstracts and papers, and reviewed and revised the manuscript. Mr JZ, Dr AB, Ms JD, Dr LMP, Ms KMR, and Dr FSW reviewed abstracts and papers, and reviewed and revised the manuscript. Ms JW conducted the initial library database search, wrote portions of the manuscript, assisted with organizing the abstract review, and reviewed and revised the manuscript. Dr NSK provided support for the project, supervised Dr Stiles-Shields, wrote portions of the manuscript, handled final submission processes, and reviewed and revised the manuscript. All authors approved the final manuscript as submitted and agree to be accountable for all aspects of the work.

Funding Dr. Stiles-Shields is supported by fellowships from the National Institutes of Health (K08 MH125069) and the Cohn Family Foundation and an R3 funding mechanism supported by Rush University Medical Center and RTI International. Mr. Zhang was supported, in part, by a Summer Medical Student Fellowship from the American Academy of Child \& Adolescent Psychiatry. Dr. Summersett Williams' effort is supported by the Agency for Health Care Research \& Quality via the ACCELERAT Program at Northwestern University (K12-HS026385). Dr. Karnik's time is supported, in part, by the National Center for Advancing Translational Science (UL1TR002389, KL2-TR002387) and the National Institute on Drug Abuse (R01-DA041071, UG1-DA049467). The content is solely the responsibility of the authors and does not necessarily represent the official views of the National Institutes of Health or the other funding entities.

\section{Declarations}

Conflict of interest The authors have no conflicts of interest to disclose.

Open Access This article is licensed under a Creative Commons Attribution 4.0 International License, which permits use, sharing, adaptation, distribution and reproduction in any medium or format, as long as you give appropriate credit to the original author(s) and the source, provide a link to the Creative Commons licence, and indicate if changes were made. The images or other third party material in this article are included in the article's Creative Commons licence, unless indicated otherwise in a credit line to the material. If material is not included in the article's Creative Commons licence and your intended use is not permitted by statutory regulation or exceeds the permitted use, you will need to obtain permission directly from the copyright holder. To view a copy of this licence, visit http://creativecommons.org/licenses/by/4.0/.

\section{References}

1. Konrad K, Firk C, Uhlhaas PJ (2013) Brain development during adolescence: neuroscientific insights into this developmental period. Dtsch Arztebl Int 110:425-431

2. Patalay P, Fitzsimons E (2018) Development and predictors of mental ill-health and wellbeing from childhood to adolescence. Soc Psychiatry Psychiatr Epidemiol 53:1311-1323

3. Casey BJ, Jones RM, Hare TA (2008) The adolescent brain. Ann N Y Acad Sci 1124:111-126

4. Paus T, Keshavan M, Giedd JN (2008) Why do many psychiatric disorders emerge during adolescence? Nat Rev Neurosci 9:947-957

5. Kessler RC, Berglund P, Demler O, Jin R, Merikangas KR, Walters EE (2005) Lifetime prevalence and age-of-onset distributions of DSM-IV disorders in the National Comorbidity Survey Replication. Arch General Psychiatry 62:593. https://doi.org/10.1001/ archpsyc.62.6.593

6. Patton GC, Coffey C, Romaniuk H, Mackinnon A, Carlin JB, Degenhardt L et al (2014) The prognosis of common mental disorders in adolescents: a 14-year prospective cohort study. Lancet 383:1404-1411

7. Kessler RC, Chiu WT, Demler O, Merikangas KR, Walters EE (2005) Prevalence, severity, and comorbidity of 12-month DSMIV disorders in the National Comorbidity Survey Replication. Arch Gen Psychiatry 62:617-627

8. Goodwin RD, Weinberger AH, Kim JH, Wu M, Galea S (2020) Trends in anxiety among adults in the United States, 2008-2018: rapid increases among young adults. J Psychiatr Res 130:441-446

9. Solmi M, Radua J, Olivola M, Croce E, Soardo L, de Pablo GS et al (2021) Age at onset of mental disorders worldwide: largescale meta-analysis of 192 epidemiological studies. Mol Psychiatry. https://doi.org/10.1038/s41380-021-01161-7

10. Ollendick TH, Hirshfeld-Becker DR (2002) The developmental psychopathology of social anxiety disorder. Biol Psychiatry 51:44-58

11. Rosellini AJ, Rutter LA, Bourgeois ML, Emmert-Aronson BO, Brown TA (2013) The relevance of age of onset to the psychopathology of social Phobia. J Psychopathol Behav Assess 35:356-365

12. Woodward LJ, Fergusson DM (2001) Life course outcomes of young people with anxiety disorders in adolescence. J Am Acad Child Adolesc Psychiatry 40:1086-1093

13. Maldonado L, Huang Y, Chen R, Kasen S, Cohen P, Chen H (2013) Impact of early adolescent anxiety disorders on self-esteem 
development from adolescence to young adulthood. J Adolesc Health 53:287-292

14. Hoffman DL, Dukes EM, Wittchen H-U (2008) Human and economic burden of generalized anxiety disorder. Depress Anxiety 25:72-90

15. Pella JE, Slade EP, Pikulski PJ, Ginsburg GS (2020) Pediatric anxiety disorders: a cost of illness analysis. J Abnorm Child Psychol 48:551-559

16. Johnston L, Miech R, O’Malley P, Bachman J, Schulenberg J, Patrick M (2019) Monitoring the future national survey results on drug use, 1975-2018: overview, key findings on adolescent drug use. Inst Soc Res. https://doi.org/10.3998/2027.42/150621

17. Mauro PM, Carliner H, Brown QL, Hasin DS, Shmulewitz D, Rahim-Juwel R et al (2018) Age differences in daily and nondaily cannabis use in the United States, 2002-2014. J Stud Alcohol Drugs 79:423-431

18. Miller AM, Rosenman R, Cowan BW (2017) Recreational marijuana legalization and college student use: early evidence. SSM Popul Health 3:649-657

19. Hansen C, Alas H. Where is Marijuana legal? A guide to marijuana legalization. US News \& World Report. 9 April 2021. https://www.usnews.com/news/best-states/articles/where-ismarijuana-legal-a-guide-to-marijuana-legalization\#: :text=Illin ois $\% 20 \% 2 \mathrm{D} \%$ 20legalization\%20measure\%20approved\%20May ,amounts\%20while\%20in\%20the\%20state.

20. Yu B, Chen X, Chen X, Yan H (2020) Marijuana legalization and historical trends in marijuana use among US residents aged 12-25: results from the 1979-2016 National Survey on drug use and health. BMC Public Health. https://doi.org/10.1186/ s12889-020-8253-4

21. Smart R, Pacula RL (2019) Early evidence of the impact of cannabis legalization on cannabis use, cannabis use disorder, and the use of other substances: findings from state policy evaluations. Am J Drug Alcohol Abuse 45:644-663

22. Levine A, Clemenza K, Rynn M, Lieberman J (2017) Evidence for the risks and consequences of adolescent Cannabis exposure. J Am Acad Child Adolesc Psychiatry 56:214-225

23. Silins E, Horwood LJ, Patton GC, Fergusson DM, Olsson CA, Hutchinson DM et al (2014) Young adult sequelae of adolescent cannabis use: an integrative analysis. Lancet Psychiatry 1:286-293

24. Macleod J, Oakes R, Copello A, Crome I, Egger M, Hickman M et al (2004) Psychological and social sequelae of cannabis and other illicit drug use by young people: a systematic review of longitudinal, general population studies. Lancet 363:1579-1588

25. Mineka S, Zinbarg R (2006) A contemporary learning theory perspective on the etiology of anxiety disorders: it's not what you thought it was. Am Psychol 61:10-26

26. Shimada-Sugimoto M, Otowa T, Hettema JM (2015) Genetics of anxiety disorders: genetic epidemiological and molecular studies in humans. Psychiatry Clin Neurosci 69:388-401

27. Courtney KE, Mejia MH, Jacobus J (2017) Longitudinal studies on the etiology of cannabis use disorder: a review. Curr Addict Rep 4:43-52

28. Gobbi G, Atkin T, Zytynski T, Wang S, Askari S, Boruff J et al (2019) Association of cannabis use in adolescence and risk of depression, anxiety, and suicidality in young adulthood: a systematic review and meta-analysis. JAMA Psychiat 76:426-434

29. Kedzior KK, Laeber LT (2014) A positive association between anxiety disorders and cannabis use or cannabis use disorders in the general population- a meta-analysis of 31 studies. BMC Psychiatry. https://doi.org/10.1186/1471-244x-14-136

30. Temple EC, Driver M, Brown RF (2014) Cannabis use and anxiety: is stress the missing piece of the puzzle? Front Psychiatry $5: 168$
31. Crippa JA, Zuardi AW, Martín-Santos R, Bhattacharyya S, Atakan $\mathrm{Z}, \mathrm{McGuire} P$ et al (2009) Cannabis and anxiety: a critical review of the evidence. Hum Psychopharmacol 24:515-523

32. Sharpe L, Sinclair J, Kramer A, de Manincor M, Sarris J (2020) Cannabis, a cause for anxiety? A critical appraisal of the anxiogenic and anxiolytic properties. J Transl Med 18:374

33. Cheung JTW, Mann RE, Ialomiteanu A, Stoduto G, Chan V, AlaLeppilampi K et al (2010) Anxiety and mood disorders and cannabis use. Am J Drug Alcohol Abuse 36:118-122

34. Ryan SA, Ammerman SD, Committee on substance use and prevention (2017) Counseling parents and teens about Marijuana use in the era of legalization of Marijuana. Pediatrics. https://doi.org/ 10.1542/peds.2016-4069

35. Hardin AP, Hackell JM, Committee on Practice and Ambulatory Medicine (2017) Age limit of pediatrics. Pediatrics. https://doi. org/10.1542/peds.2017-2151

36. Tricco AC, Lillie E, Zarin W, O'Brien KK, Colquhoun H, Levac D et al (2018) PRISMA Extension for Scoping Reviews (PRISMA-ScR): checklist and explanation. Ann Internal Med 169:467-473. https://doi.org/10.7326/m18-0850

37. Covidence systematic review software. Veritas Health Innovation, Melbourne. http://www.covidence.org

38. Leadbeater BJ, Ames ME, Linden-Carmichael AN (2019) Age-varying effects of cannabis use frequency and disorder on symptoms of psychosis, depression and anxiety in adolescents and adults. Addiction 114:278-293. https://doi.org/10.1111/add. 14459

39. Thompson K, Merrin GJ, Ames ME, Leadbeater B (2018) Marijuana trajectories in Canadian youth: associations with substance use and mental health. Can J Behav Sci 50:17-28

40. Hellemans KGC, Wilcox J, Nino JN, Young M, McQuaid RJ (2019) Cannabis use, anxiety, and perceptions of risk among canadian undergraduates: the moderating role of gender. Can J Addict 10:22

41. Cerdá M, Bordelois PM, Keyes KM, Galea S, Koenen KC, Pardini D (2013) Cumulative and recent psychiatric symptoms as predictors of substance use onset: does timing matter? Addiction 108:2119-2128

42. Cloak CC, Alicata D, Ernst TM, Chang L (2015) Psychiatric symptoms, salivary cortisol and cytokine levels in young marijuana users. J Neuroimmune Pharmacol 10:380-390

43. Schuster RM, Hareli M, Moser AD, Lowman K, Gilman J, Ulysse C et al (2019) Cross-domain correlates of cannabis use disorder severity among young adults. Addict Behav 93:212-218

44. Keith DR, Hart CL, McNeil MP, Silver R, Goodwin RD (2015) Frequent marijuana use, binge drinking and mental health problems among undergraduates. Am J Addict 24:499-506

45. Degenhardt L, Coffey C, Romaniuk H, Swift W, Carlin JB, Hall WD et al (2013) The persistence of the association between adolescent cannabis use and common mental disorders into young adulthood. Addiction 108:124-133. https://doi.org/10.1111/j. 1360-0443.2012.04015.x

46. Kaasbøll C, Hagen R, Gråwe RW (2018) Population-based associations among cannabis use, anxiety, and depression in norwegian adolescents. J Child Adolesc Subst Abuse 27:238-243

47. Duperrouzel J, Hawes SW, Lopez-Quintero C, Pacheco-Colón I, Comer J, Gonzalez R (2018) The association between adolescent cannabis use and anxiety: a parallel process analysis. Addict Behav 78:107-113

48. Rusby JC, Westling E, Crowley R, Mills KL, Light JM (2019) Associations between marijuana use and anxious mood lability during adolescence. Addict Behav 92:89-94

49. Hill S, Shanahan L, Costello EJ, Copeland W (2017) Predicting persistent, limited, and delayed problematic cannabis use in early 
adulthood: findings from a longitudinal study. J Am Acad Child Adolesc Psychiatry 56:966-974.e4

50. Ecker AH, Buckner JD (2014) Cannabis use behaviors and social anxiety: the roles of perceived descriptive and injunctive social norms. J Stud Alcohol Drugs 75:74-82

51. Foster DW, Garey L, Buckner JD, Zvolensky MJ (2016) Social anxiety and cannabis-related impairment: the synergistic influences of peer and parent descriptive and injunctive normative perceptions. Subst Use Misuse 51:912-921

52. Villarosa-Hurlocker MC, Bravo AJ, Pearson MR, Protective Strategies Study Team (2019) The relationship between social anxiety and alcohol and marijuana use outcomes among concurrent users: a motivational model of substance use. Alcohol Clin Exp Res 43:732-740

53. Ecker AH, Buckner JD (2018) Cannabis-related problems and social anxiety: the mediational role of post-event processing. Subst Use Misuse 53:36-41

54. Stapinski LA, Montgomery AA, Araya R (2016) Anxiety, depression and risk of cannabis use: examining the internalising pathway to use among Chilean adolescents. Drug Alcohol Depend 166:109-115

55. Laguerre C-E, Vavassori D, Fernandez L (2015) Parental contributions and separation anxiety on adolescents' cannabis use: a preliminary study based on French high school students. J Addict Nurs 26:3-7

56. Keough MT, Hendershot CS, Wardell JD, Bagby RM (2018) Investigating the mediational role of negative urgency in the anxiety sensitivity pathway to cannabis problems and dependence symptoms among postsecondary students. J Am Coll Health 66:69-75. https://doi.org/10.1080/07448481.2017.1369093

57. Pang RD, Guillot CR, Zvolensky MJ, Bonn-Miller MO, Leventhal AM (2017) Associations of anxiety sensitivity and emotional symptoms with the subjective effects of alcohol, cigarettes, and cannabis in adolescents. Addict Behav 73:192-198

58. Hines LA, Freeman TP, Gage SH, Zammit S, Hickman M, Cannon $\mathrm{M}$ et al (2020) Association of high-potency cannabis use with mental health and substance use in adolescence. JAMA Psychiat 77:1044-1051

59. Otten R, Huizink AC, Monshouwer K, Creemers HE, Onrust S (2017) Cannabis use and symptoms of anxiety in adolescence and the moderating effect of the serotonin transporter gene. Addict Biol 22:1081-1089

60. Wolitzky-Taylor K, McBeth J, Guillot CR, Stone MD, Kirkpatrick MG, Zvolensky MJ et al (2016) Transdiagnostic processes linking anxiety symptoms and substance use problems among adolescents. J Addict Dis 35:266-277

61. Bierhoff J, Haardörfer R, Windle M, Berg CJ (2019) Psychological risk factors for alcohol, cannabis, and various tobacco use among young adults: a longitudinal analysis. Subst Use Misuse 54:1365-1375

62. Schmits E, Maurage P, Thirion R, Quertemont E (2015) Dissociation between implicit and explicit expectancies of cannabis use in adolescence. Psychiatry Res 230:783-791

63. Ali A, Carré A, Hassler C, Spilka S, Vanier A, Barry C et al (2016) Risk factors for substances use and misuse among young people in France: what can we learn from the Substance Use Risk Profile Scale? Drug Alcohol Depend 163:84-91

64. Di Blasi M, Pavia L, Cavani P, Lo Verso G, Schimmenti A (2015) Cannabis use and social anxiety in adolescence: the role of facilitation expectancies. J Child Adolesc Subst Abuse 24:397-404

65. Schmits E, Mathys C, Quertemont E (2016) Is social anxiety associated with cannabis use? The role of cannabis use effect expectancies in middle adolescence. J Child Adolesc Subst Abuse 25:348-359

66. Schmits E, Mathys C, Quertemont E (2015) A longitudinal study of cannabis use initiation among high school students: effects of social anxiety, expectancies, peers and alcohol. J Adolesc $41: 43-52$

67. Schmits E, Quertemont E (2018) Components of social anxiety prevent cannabis use in adolescents. J Subst Use 23:441-450

68. Cerdá M, Prins SJ, Galea S, Howe CJ, Pardini D (2016) When psychopathology matters most: identifying sensitive periods when within-person changes in conduct, affective and anxiety problems are associated with male adolescent substance use. Addiction 111:924-935

69. Colder CR, Lee YH, Frndak S, Read JP, Wieczorek WF (2019) Internalizing symptoms and cannabis and alcohol use: betweenand within-person risk pathways with coping motives. J Consult Clin Psychol 87:629-644

70. Gage SH, Hickman M, Heron J, Munafò MR, Lewis G, Macleod $\mathrm{J}$ et al (2015) Associations of cannabis and cigarette use with depression and anxiety at age 18: findings from the Avon Longitudinal Study of Parents and Children. PLoS ONE 10:e122896

71. Grunberg VA, Cordova KA, Bidwell LC, Ito TA (2015) Can marijuana make it better? Prospective effects of marijuana and temperament on risk for anxiety and depression. Psychol Addict Behav 29:590-602

72. Ninnemann AL, Choi HJ, Stuart GL, Temple JR (2017) Longitudinal predictors of synthetic cannabinoid use in adolescents. Pediatrics 139:e20163009. https://doi.org/10.1542/peds.2016-3009

73. Osuch E, Vingilis E, Ross E, Forster C, Summerhurst C (2013) Cannabis use, addiction risk and functional impairment in youth seeking treatment for primary mood or anxiety concerns. Int J Adolesc Med Health 25:309-314. https://doi.org/10.1515/ ijamh-2013-0067

74. Phillips KT, Phillips MM, Duck KD (2018) Factors associated with marijuana use and problems among college students in Colorado. Subst Use Misuse 53:477-483. https://doi.org/10.1080/ 10826084.2017.1341923

75. Rahm-Knigge RL, Prince MA, Conner BT (2019) Clarifying the relation between social interaction anxiety and cannabis use: personality as a distinguishing factor. Subst Us Misuse 54:20012012. https://doi.org/10.1080/10826084.2019.1626431

76. Walters KS, Bulmer SM, Troiano PF, Obiaka U, Bonhomme R (2018) Substance use, anxiety, and depressive symptoms among college students. J Child \& Adolesc Subst Abuse 27:103-111. https://doi.org/10.1080/1067828x.2017.1420507

77. Wright NE, Scerpella D, Lisdahl KM (2016) Marijuana use is associated with behavioral approach and depressive symptoms in adolescents and emerging adults. PLoS ONE 11:e0166005

78. Khoddam R, Jackson NJ, Leventhal AM (2016) Internalizing symptoms and conduct problems: redundant, incremental, or interactive risk factors for adolescent substance use during the first year of high school. Drug Alcohol Depend 169:48-55. https:// doi.org/10.1016/j.drugalcdep.2016.10.007

79. Cloutier RM, Blumenthal H, Mischel ER (2016) An examination of social anxiety in marijuana and cigarette use motives among adolescents. Subst Use Misuse 51:408-418

80. Ecker AH, Richter AA, Buckner JD (2014) Cannabis-related impairment: the impacts of social anxiety and misconceptions of friends' cannabis-related problems. Addict Behav 39:1746-1749

81. Elkington KS, Cruz JE, Warne P, Santamaria EK, Dolezal C, Mellins CA (2016) Marijuana use and psychiatric disorders in perinatally HIV-exposed youth: does HIV matter? J Pediatr Psychol 41:277-286

82. Buckner JD, Ecker AH, Dean KE (2016) Solitary cannabis use frequency mediates the relationship between social anxiety and cannabis use and related problems. Am J Addict 25:99-104

83. Gillen CTA, Barry CT, Bater LR (2016) Anxiety symptoms and coping motives: examining a potential path to substance userelated problems in adolescents with psychopathic traits. Subst Use Misuse 51:1920-1929 
84. Butler A, Patte KA, Ferro MA, Leatherdale ST (2019) Interrelationships among depression, anxiety, flourishing, and cannabis use in youth. Addict Behav 89:206-215
Publisher's Note Springer Nature remains neutral with regard to jurisdictional claims in published maps and institutional affiliations. 